\title{
Secondary Structures of Peptides and Proteins via NMR Chemical Shielding Anisotropy (CSA) Parameters
}

\section{Supporting Information}

\author{
Eszter Czinki, ${ }^{a}$ Attila G. Császár, ${ }^{a}$ Gábor Magyarfalvi, ${ }^{a}$ Peter R. \\ Schreiner, ${ }^{b}$ and Wesley D. Allen ${ }^{c, *}$ \\ ${ }^{a}$ Laboratory of Molecular Spectroscopy, \\ Institute of Chemistry, Eötvös University, \\ H-1518 Budapest 112, P. O. Box 32, Hungary \\ e-mail: csaszar@chem.elte.hu \\ ${ }^{\mathrm{b}}$ Institute of Organic Chemistry, Justus-Liebig University, Heinrich-Buff-Ring 58, 35392 \\ Giessen, Germany \\ ${ }^{\mathrm{c}}$ Center for Computational Chemistry, Department of Chemistry, \\ University of Georgia, Athens, GA 30602, U.S.A. \\ e-mail:wdallen@uga.edu
}


Complete Ref. 69:

Gaussian 98, Revision A.9, M. J. Frisch, G. W. Trucks, H. B. Schlegel, G. E. Scuseria, M. A. Robb, J. R. Cheeseman, V. G. Zakrzewski, J. A. Montgomery, Jr., R. E. Stratmann, J. C. Burant, S. Dapprich, J. M. Millam, A. D. Daniels, K. N. Kudin, M. C. Strain, O. Farkas, J. Tomasi, V. Barone, M. Cossi, R. Cammi, B. Mennucci, C. Pomelli, C. Adamo, S. Clifford, J. Ochterski, G. A. Petersson, P. Y. Ayala, Q. Cui, K. Morokuma, D. K. Malick, A. D. Rabuck, K. Raghavachari, J. B. Foresman, J. Cioslowski, J. V. Ortiz, A. G. Baboul, B. B. Stefanov, G. Liu, A. Liashenko, P. Piskorz, I. Komaromi, R. Gomperts, R. L. Martin, D. J. Fox, T. Keith, M. A. Al-Laham, C. Y. Peng, A. Nanayakkara, M. Challacombe, P. M. W. Gill, B. Johnson, W. Chen, M. W. Wong, J. L. Andres, C. Gonzalez, M. Head-Gordon, E. S. Replogle, and J. A. Pople, Gaussian, Inc., Pittsburgh PA, 1998. 